\title{
SURGICAL TREATMENT OF VENTRAL FORAMEN MAGNUM MENINGIOMAS
}

\author{
Danilo Otávio de Araújo Silva , Leonardo Ferraz Costa ${ }^{7}$, Matheus Augusto Pinto Kitamura', \\ Divaldo de Arruda Câmara Júnior ', Joacil Carlos da Silva², Hildo Rocha Cirne de Azevedo Filho²
}

Foramen magnum meningiomas ( FMM) are rare tumors. They represent around $3 \%$ of all meningiomas ${ }^{1-4}$. According to the literature, these tumors are among the most challenging meningiomas to treat. The main classification system of these lesions depends whether the tumor is anterior or posterior to the first dentate ligament ${ }^{4}$. The localization of the tumor determines the surgical approach. FMM are slow growing tumors, the clinical presentation is often a long history of occipitocervical pain associated with long tract signs and lower cranial nerve deficits $^{5-10}$. The treatment of choice is surgical removal, when the patient's clinical conditions allows that option. Debate exists about the best surgical approach and how much bone resection should be made to accomplish the ideal exposure ${ }^{1,6,7,9}$. It is consensus that the early diagnose is the most important issue to insure a good outcome.

We report two cases of ventral FMM that were successfully treated with surgical resection without adding any new neurologic deficits to the patient. Permission publication was granted by the institutional ethical committee.

\section{CASES}

Case 1

A 54 years-old woman was admitted with long lasting history of occipitocervical headache and gait disturbance recently associated with respiratory distress. The neurologic examination showed grade III quadriparesis, global hyperreflexia and hypertonia, bilateral Hoffman and Babinski signs, decreased sensation to light touch on bilateral distal extremities and lower cranial nerves deficits.

The magnetic resonance (MR) imaging evidenced ventrolateral FMM (Fig1). The angiography study revealed no encasement of the vertebral arteries and no venous or dural sinus malformations.

The surgical resection was performed with no complications. An extreme far lateral transcondylar approach with removal of the posterior third of the occipital condyle was done without any damage to the vital neurovascular structures in the

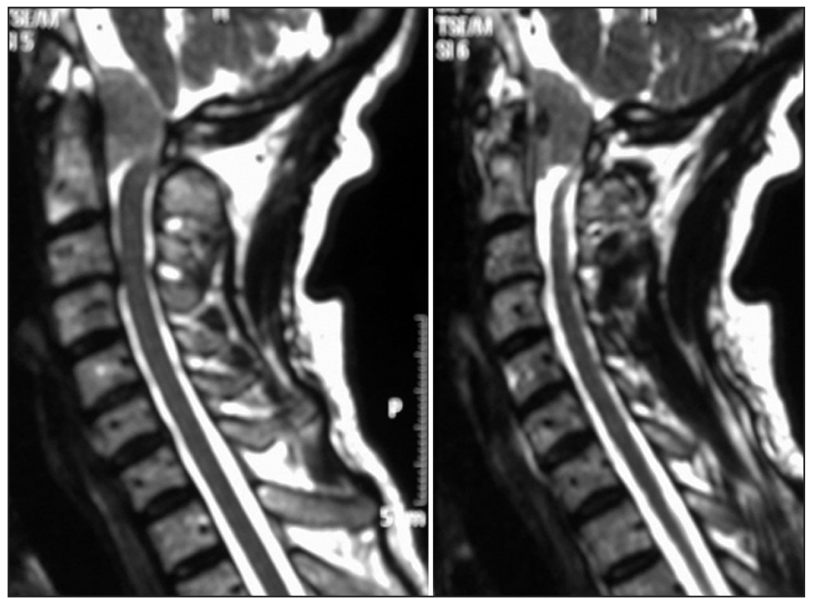

Fig 1. Case 1: Pre operative magnetic resonance sagital T2 weighted images.

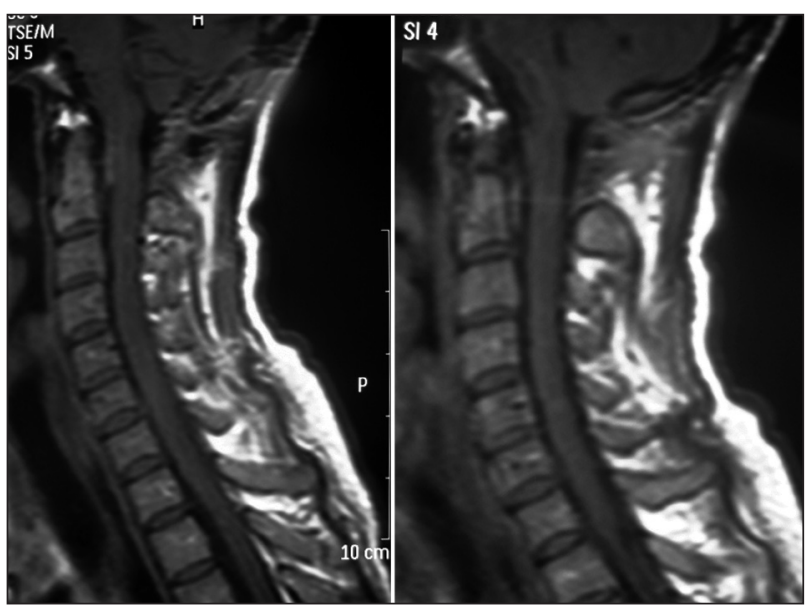

Fig 2. Case 1: 6 months post operative magnetic resonance sagital $T 7$ weighted images.

foramen magnum region. The resection of the ipsilateral posterior arch of $\mathrm{Cl}$ was carefully conducted. The tumor was completely removed (Fig 2).

The patient was discharged and no neurological deficits were added to her by the surgical procedure. The motor weakness

TRATAMENTO CIRÚRGICO DE MENINGIOMAS VENTRAIS DO FORAME MAGNO

Restauração Hospital, Recife PE, Brazil: 'Neurosurgery Resident; ${ }^{1}$ Neurosurgeon.

Received 8 June 2009. Accepted 27 July 2009.

Dr. Danilo Otávio de Araújo Silva - Rua Paissandu 200 / 401 - 50070-200 Recife PE - Brasil.E-mail: daniloncr@gmail.com 


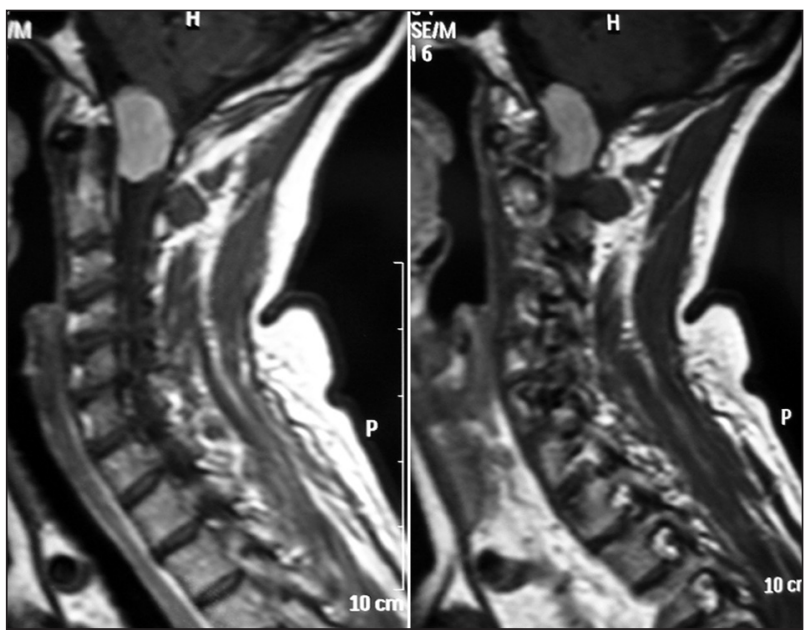

Fig 3. Case 2: Pre operative magnetic resonance sagital $T 1$ weighted images.

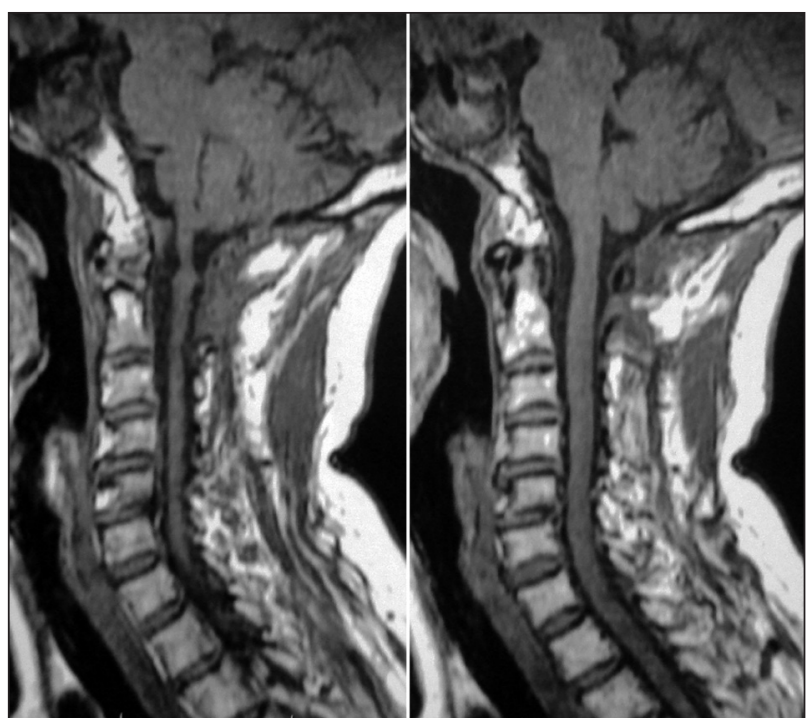

Fig 4. Case 2: 6 months post operative magnetic resonance sagital 77 weighted images.

started to improve by the first month after surgery. She is now been evaluated at the physical therapy and fonoaudiology department with great improvement in the previous symptoms.

\section{Case 2}

A 64 years old woman presented to our institution with a main complaint of occipitocervical pain. The neurologic examination revealed only bilateral Hoffman sign. There were no gait disturbance, lower cranial nerve deficits, motor weakness or decreased sensibility of any kind. MR demonstrated a ventrolateral FMM (Fig 3). Again, the angiographic study was performed and no encasement of the vertebral arteries or venous anomalies were present.

The patient was submitted to a lateral suboccipital approach with no resection of the occipital condyle, associated to $\mathrm{Cl}$ and $\mathrm{C2}$ hemilaminectomy. We were able to achieve total resection (Fig 4).
The patient was discharged with great improvement of the occipitocervical pain and neurologically intact.

\section{DISCUSSION}

FMM are uncommon tumors in unique and delicate localization. The best treatment is surgical removal, however it is yet to be define the most appropriate surgical approach to ventral type of $\mathrm{FMM}^{1-9}$. FMM, like all meningiomas, are more frequent in women, with a female/male rate of 2.6:1. They are estimate to represent around $3 \%$ of all meningiomas, but they are the most common benign extramedullary tumor of the craniospinal transition ${ }^{4}$.

Boulton and Cusimano ${ }^{10}$ reported an anatomical study to compare the area of surgical exposure achieved using retrosigmoid or far lateral transcondylar approaches. Thirteen embalmed cadaveric heads were dissected bilaterally via the retrosigmoid approach on one side and the far lateral approach on the other. The circumference of the area of exposure was delineated using beaded pins placed into the dura. After removal of the brain, the longest longitudinal and transverse axes of the pinned areas were measured and surface area calculated. The area of surgical exposure was also expressed as a percentage of the total area of the lower clivus. Normalized and adjusted surface areas were calculated using the bimastoid diameter. The mean area of exposure required using the retrosigmoid approach was $19.8 \pm 14.7 \mathrm{~mm}^{2}$ (range 6-49 $\mathrm{mm}^{2}$ ) and that using the far lateral approach was $27.8 \pm 22.8 \mathrm{~mm}^{2}$ (range 10-90 $\mathrm{mm}^{2}$ ). The mean percentage of the lower clivus exposed by the retrosigmoid approach was $14.9 \pm 3.6 \%$ (range 10-22\%) and that exposed by the far lateral approach was $20.5 \pm 4.9 \%$ (range $10-25 \%$ ). The far lateral approach provided significantly greater area of operative exposure and allowed a significantly higher percentage of lower clivus and foramen magnum exposure than did the retrosigmoid approach $(p<0.05)$. Normalized and adjusted surface areas, taking into consideration the bimastoid diameter, were also statistically significant in favor of the far lateral approach. The authors conclude that the far lateral transcondylar approach gives more room to work at the lower clivus and foramen magnum areas and it should be the best route for removing FMM'.

Most of the series agree that far lateral approach should be the first choice in these cases. Nevertheless, there are different opinions regarding how much of the occipital condyle should be removed. Most authors consider that it should be individualized in each case. In some instances no removal at all would be necessary ${ }^{6,7,9}$, and in other occasions the posterior third of the occipital condyle or even the posterior half of it should be resected ${ }^{2,3,4,5,8}$. Factors that would indicate the extension of bone resection are size and location of the tumor ${ }^{2,4}$ and anatomical relation (superior or inferior) to the vertebral artery ${ }^{3}$. 
We report two cases illustrating that the partial condylectomy can be individualized in particular cases. In the first one, it would not had been possible to remove the tumor without excessive brainstem retraction if the posterior third of the occipital condyle had not been removed. However, in the second case, there was enough room to work in a good operative field and remove the tumor, because the retraction provided by the tumor its self on the brainstem gave us a great surgical corridor to perform complete resection.

In summary, we believe that with careful microsurgical techniques it is possible to remove FMMs with no partial condilectomy. Meanwhile, the surgical team should be able to do it when necessary. It is our impression that the transcondylar extension should be reserved to small tumors that do not displace the neural structures enough to create an adequate surgical corridor.

\section{REFERENCES}

1. Suhardja A, Agur AM, Cusimano MD. Anatomical basis of approaches to foramen magnum and lower clival meningiomas: comparison of retrosigmoid and transcondylar approaches. Neurosurg Focus 2003; 14:e9.

2. Samii M, Klekamp J, Carvalho G. Surgical results for meningiomas of the craniocervical junction. Neurosurgery 1996;39:1086-1094.

3. George B, Lot G, Boissonnet H. Meningioma of the foramen magnum: a series of 40 cases. Surg Neurol 1997;47:371-379.

4. Arnautovic' KI, Al-Mefty O, Husain M. Ventral foramen magnum meningiomas. J Neurosurg 2000;92:71-80.

5. Gupta SK, Sharma BS, Khosla VK, Mathuriya SN, Pathak A, Tewari MK. Far lateral approach for foramen magnum lesions. Neurol Med Chir 2000;40:48-52.

6. Goel A, Desai K, Muzumdar D. Surgery on anterior foramen magnum meningiomas using a conventional posterior suboccipital approach: a report on an experience with 17 cases. Neurosurgery 2001;49:102-106.

7. Nanda A, Vincent DA, Vannemreddy PS, Baskaya MK, Chanda A. Far lateral approach to intradural lesions of the foramen magnum without resection of the occipital condyle. J Neurosurg 2002;96:302-309.

8. Pamir MN, Kiliç T, Ozduman K, Türe U. Experience of a single institution treating foramen magnum meningiomas. J Clin Neurosci 2004;11: 863-867.

9. Bassiouni H, Ntoukas V, Asgari S, Sandalcioglu EI, Stolke D, Seifert V. Foramen magnum meningiomas: clinical outcome after microsurgical resection via a posterolateral suboccipital retrocondylar approach. Neurosurgery 2006;59:1177-1185.

10. Boulton MR, Cusimano MD. Foramen magnum meningiomas: concepts, classifications and nuances. Neurosurg Focus 2003;14:e10. 